\title{
Análise Técnica do Uso de Resíduos de Poliéster na Indústria Têxtil
}

\author{
Eleandro B. Pinho, Helson M. da Costa \\ Departamento de Materiais, Instituto Politécnico, UERJ \\ Valéria D. Ramos \\ Universidade Estácio de Sá, UNESA
}

Resumo: Nesta investigação, fios e tecidos foram fabricados a partir da mistura de resíduos pós-consumo de poli(tereftalato de etileno) (PET), resíduos da reciclagem primária de poliéster convencional e elastano. As propriedades físico-químicas foram obtidas e comparações com fios e tecidos de poliéster comercial/elastano foram feitas. Os resultados mostraram que é viável produzir fios a partir dos resíduos utilizando-se os mesmos procedimentos adotados na indústria têxtil para o produto comercial.

Palavras-chave: Poli(tereftalato de etileno), reciclagem, indústria têxtil.

\section{Technical Analysis of the Use of Polyester Wastes in Textile Industry}

\begin{abstract}
In this investigation, yarns and clothes were made from blending of post-consumer wastes of poly(ethylene terephthalate) (PET), wastes from primary recycling of conventional polyester and elastane. The physicochemical properties were obtained and comparisons with yarns and clothes of commercial polyester/elastane have been made. The results show it is feasible to produce yarns from waste using the same procedures used in the textile industry for the commercial product.
\end{abstract}

Keywords: Poly(ethylene terephthalate), recycling, textile industry.

\section{Introdução}

A indústria do plástico é um dos setores da economia que mais se desenvolveu nos últimos anos. Produtos feitos a base de termoplásticos são utilizados em quase todos os setores da economia, como a construção civil, telecomunicações, eletroeletrônica, automobilística, médico-hospitalar e energia ${ }^{[1-5]}$.

Atualmente, o setor de embalagens é o que mais se destaca, consumindo aproximadamente $30 \%$ das resinas plásticas. Apesar dos visíveis benefícios do uso de produtos plásticos, uma das críticas em relação a sua utilização é a sua baixíssima biodegradabilidade ambiental. Os resíduos plásticos pós-consumo são fontes de poluição que causam inúmeros problemas ambientais e também representam um desafio para o gerenciamento do lixo em grandes cidades ${ }^{[1-5]}$.

A reciclagem de resíduos permitiria, em parte, solucionar o problema ambiental bem como possibilitaria o desenvolvimento de novos materiais a partir de blendas e compósitos que agregam maior valor ao material pós-consumo $^{[1-5]}$.

No caso do poli(tereftalato de etileno) (PET), o reaproveitamento de resíduos pode ser feito por meio de reciclagem mecânica (primária ou secundária), química (terciária) e energética (quaternária). A evolução do mercado de PET no Brasil e os avanços tecnológicos têm impulsionado diversas aplicações para o PET reciclado, tais como a produção de cordas, fios, carpetes, entre outros. Há ainda, a possibilidade de uso do PET pós-consumo em embalagens alimentícias, desde que obtido por meio de uma tecnologia de reciclagem física e/ou química com alta eficiência de descontaminação ${ }^{[6,7]}$.

Atualmente a fibra têxtil feita de garrafa PET reciclada possui a denominação de poliéster reciclado. Na transformação do poliéster reciclado utiliza-se cerca de $30 \%$ da energia utilizada na produção da fibra virgem, ou seja, além da própria reciclagem que contribui para a redução de resíduos, a economia no uso de energia também é um ativo ambiental desse produto. Em média, para se confeccionar uma camiseta, utiliza-se uma quantidade de fibra reciclada que corresponde a duas garrafas $\mathrm{PET}^{[7-9]}$.

Este artigo tem como objetivo estudar a viabilidade técnica de produção de tecidos fabricados com uma fibra têxtil obtida a partir da mistura de resíduos de PET reciclado/resíduos de poliéster convencional/elastano comercial, a qual será denominada de PETr. Os resíduos utilizados neste trabalho foram provenientes não apenas de embalagens e garrafas de bebidas carbonatadas pós-consumo, mas também da reciclagem primária do poliéster da própria indústria têxtil. A fibra têxtil e o tecido obtido foram comparados através da fiabilidade, tecimento, tingimento e ensaios mecânicos, comumente utilizados na indústria têxtil, com a fibra de poliéster/ elastano comercial, a qual será denominada de PETc, e o respectivo tecido.

Autor para correspondência: Helson M. da Costa, Departamento de Materiais - DEMAT, Instituto Politécnico - IPRJ, 


\section{Experimental}

\section{Materiais e processamento}

Os resíduos sólidos de PET (embalagens e garrafas de bebidas carbonatadas) foram coletados junto aos centros de coleta seletiva e manufaturados pela empresa UNIFI (Alfenas/MG). A partir de tais resíduos, foram obtidos fios de PET título 78/48 dtex* que representa $90,4 \%$ do tecido. O poliéster reciclado foi proveniente da reciclagem primária conduzida na própria empresa UNIFI. A fibra de elastano foi fornecida pela empresa Triumph International (Nova Friburgo-RJ); FIO: PUE 22 dtex, que representa $9,6 \%$ do tecido. A titulação dos fios foi feita pelo método Skein conforme a norma ASTM D1907-07.

O processo de manufatura do PET reciclado pode ser descrito simplificadamente da seguinte maneira: depois de recolhidas, as garrafas foram lavadas e separadas por cores, rótulos e tampas foram retirados. Após a secagem, as etapas seguintes foram fusão à temperatura de $300{ }^{\circ} \mathrm{C}$ e, em seguida, filtragem. Para a produção da fibra, houve a necessidade de uma nova fusão e processamento em equipamentos como extrusoras e fiadoras (fiação ou spinning) para separação em filamentos. Por último, realizou-se o estiramento, transformando a fibra em fio (yarn). Vale ressaltar que mesmo com todos os riscos de contaminação por impurezas que existe numa reciclagem, ainda assim foi possível obter um fio com título semelhante à titulação de uma microfibra.

O processo de obtenção do tecido foi semelhante ao do tecimento convencional de poliéster. $\mathrm{O}$ acompanhamento do processo revelou que no tecimento não houve nenhum problema de produção. A confecção de malhas com os fios de PET e poliéster reciclado misturado aos de elastano ocorreu nas empresas Triumph International em Nova Friburgo. Foram confeccionados tecidos com características semelhantes aos do tecido convencional de poliéster/elastano, utilizando-se uma máquina circular de monofrontura (aparelho para fazer meiamalha convencional) com as seguintes especificações de confecção: finura 32"; largura 30"; tiragem 52,3 cm/min; largura do rolo $1,0 \mathrm{~m}$; metragem do tecido $120 \mathrm{~m}$.

\section{Tingimento}

A tecnologia de incorporação de pigmentos é baseada na ancoragem mecânica das partículas de pigmento sobre a fibra, enquanto a tecnologia do tingimento com corantes é baseada em processos de equilíbrio físico-químico, nominalmente difusão e sorção de moléculas de corantes ou íons. Esses processos podem ser seguidos ou não por reações químicas no substrato ${ }^{[9,10]}$.

A transposição dos corantes dispersos na fibra de PET envolveu certa dificuldade em função de a estrutura ser cristalina e altamente orientada. Assim sendo, o tingimento foi conduzido através do processo HT. Em tal processo, o tingimento é realizado por esgotamento,

* A unidade tex de um fio é igual à massa em gramas de 1.000 metros de fio ou de qualquer outro material têxtil. É a representação recomendada pelo Sistema Internacional de Unidades (SI). em aparelhos fechados, em temperaturas de $135^{\circ} \mathrm{C}$ e sob pressão de aproximadamente 3,5 atmosferas. O poliéster em alta temperatura adquire maior mobilidade em suas regiões amorfas e com o surgimento de maiores espaços livres entre os segmentos poliméricos, a difusão do corante é facilitada ${ }^{[10]}$.

O método por esgotamento ocorreu de forma descontínua e resumidamente seguiu as seguintes etapas:

- Etapa I: Em um autoclave, uma meia-malha foi submetida a um banho contendo concentrações de $1,0 \mathrm{~g} / \mathrm{L}$ de agente emulagador ${ }^{* *}$ e agente antiquebradura $^{* * *}$. Após cinco minutos, ácido cítrico em concentração $0,4 \mathrm{~g} / \mathrm{L}$ foi adicionado e o sistema aquecido até $60{ }^{\circ} \mathrm{C}$;

- Etapa II: Os corantes comerciais Amarelo disperso S-WF, Rubi disperso S-WF e Azul disperso S-WF foram adicionados em quantidades de $0,1100 \%$, $0,0278 \%$ e 0,0375\%, respectivamente. Após a dosagem dos corantes, a temperatura do banho foi elevada a $135^{\circ} \mathrm{C}$ usando-se uma taxa de aquecimento de $1,5{ }^{\circ} \mathrm{C} / \mathrm{min}$. A temperatura foi mantida por 45 minutos e, então, procedeu-se o resfriamento até $60{ }^{\circ} \mathrm{C}$;

- Etapa III: O término da operação de tingimento deu-se através lavagens em ciclos de aquecimento $\left(\cong 90{ }^{\circ} \mathrm{C}\right)$ e resfriamento $\left(\cong 60{ }^{\circ} \mathrm{C}\right)$ com auxílio de agente antiquebradura e um detergente, ambos em concentrações de 1,0 g/L. Para o acabamento final foi utilizada 5,0 g/L de uma microemulsão de silicone.

O poder de tingimento dos fios de PET reciclado/ resíduos de poliéster/elastano foi avaliado segundo o sistema Smart Liquor, o qual é um sistema para análise e otimização de processos de tingimento. Ele consiste em um espectrofotômetro com diversos acessórios para medidas contínuas tanto em linha como individuais. Para a avaliação da montagem do tingimento, as amostras foram retiradas do banho em diferentes períodos. Nesta avaliação, foram utilizadas cinco amostras de fios PETc e $P E T r$, tendo sido realizadas três réplicas.

\section{Ensaios físico-químicos}

Após a confecção dos tecidos e o processo de tingimento, os ensaios físico-químicos foram conduzidos nos laboratórios do SENAI/CETIQT . Os ensaios realizados foram:

- Método para determinação da carga de ruptura e do alongamento no ponto de ruptura para fios (ISO 2062/2009) $)^{[11]}$;

- Ensaios para a solidificação da $\operatorname{cor}^{[12-19]}$ : nesses ensaios foram verificadas eventuais modificações nas cores dos tecidos motivadas por agentes externos como, por exemplo, lavagem, suor, água do mar, água clorada, fricção, luz solar entre outros. Estes problemas, quando ocorrem, evidenciam falhas no processo de tingimento e produzem manchas ou desbote, gerando prejuízos irreparáveis à aparência do tecido. A solidez da cor foi simulada em laboratório.

\footnotetext{
** É um emulsificante para a obtenção de emulsões do tipo óleo em água para estamparia com pigmentos.

*** Inibidores de vincos, ou agentes antiquebraduras, provêem boas propriedades antifricção nos processos úmidos e reduzem o impacto mecânico durante os processos de tingimento.
} 
Segue a descrição de algumas dessas características alvo do estudo neste trabalho:

- Solidez da cor ao suor: determinou-se a característica que o tecido possui de alterar e transferir a sua cor após contato com soluções que simularam os efeitos do suor, tanto ácido quanto alcalino;

- Solidez da cor à lavagem: determinou-se a característica que o tecido possui de alterar ou transferir a sua cor após ser submetido a um procedimento que simulou a ação de cinco lavagens;

- Solidez da cor à água clorada de piscina: O ensaio consistiu em submeter corpos de prova, de dimensões padronizadas, à solução que simulou as condições de água clorada de piscina, avaliando-se, posteriormente, se houve a transferência ou alteração de cor, por meio de uma escala padrão;

- Solidez da cor à água do mar: O ensaio consistiu em submeter corpos de prova, de dimensões padronizadas, à solução que simulou as condições da água do mar, avaliando-se, posteriormente, se houve a transferência ou alteração de cor, por meio de uma escala padrão;

- Solidez da cor à fricção: o ensaio determinou a característica que o tecido possui de transferir a sua cor após ser friccionado contra um tecido branco;

- Solidez da cor à luz $(40 \mathrm{~h})$ : determinou-se a característica que o tecido possui de alterar ou não a sua cor mediante a exposição à luz artificial representativa em relação à luz solar.

\section{Resultados e Discussão}

\section{Análise do processo de tingimento dos fios de PETC e PETr}

Durante o processo de tingimento três etapas são consideradas importantes: a montagem, a fixação e o tratamento final. A fixação do corante à fibra é feita através de reações químicas, da simples insolubilização do corante ou de derivados gerados, e ocorre usualmente em diferentes etapas durante a fase de montagem e fixação. Entretanto, todo processo de tintura envolve, como operação final, uma etapa de lavagem em banhos correntes para retirada do excesso de corante original ou corante hidrolisado não fixado à fibra nas etapas precedentes $^{[9,10]}$.

Na Tabela 1 são apresentados os dados do teste Smart Liquor, o qual mede o percentual de esgotamento do corante no banho, ou seja, medida da razão de montagem do corante na fibra (o programa do próprio equipamento calculou a média dos cinco corpos de provas ensaiados para cada amostra). Estão apresentados apenas os resultados dos tingimentos dos corpos de prova das amostras que obtiveram diferenças significativas.

O teste $t$ de Student é uma ferramenta estatística utilizada com muita frequência para expressar intervalos de confiança e para a comparação de resultados de experimentos diferentes ${ }^{[20]}$. O teste $t$ foi aplicado aos dados da Tabela 1 para verificar se os fios de PET $c$ e PET $r$ foram equivalentes quanto ao tingimento.

Usando-se os valores médios para os corantes vermelho, amarelo e azul dos fios de PETc como
Tabela 1. Resultados do ensaio Smart Liquor para os fios de PETc (poliéster comercial/elastano) e PETr (resíduos de PET/ resíduos de poliéster/elastano).

\begin{tabular}{lcccc}
\hline \multicolumn{5}{c}{ Percentual de rendimento do corante disperso (\%) } \\
\hline Ensaio & $\begin{array}{c}\text { Tingimento } \\
\mathbf{1}\end{array}$ & $\begin{array}{c}\text { Tingimento } \\
\mathbf{2}\end{array}$ & $\begin{array}{c}\text { Tingimento } \\
\mathbf{3}\end{array}$ & Média \\
\hline \multicolumn{5}{c}{ PET $\boldsymbol{c}$} \\
\hline Corante & \multicolumn{5}{c}{85,3} & $86,1 \pm 1,3$ \\
\hline Vermelho & 87,6 & 85,5 & 89,9 & $90,4 \pm 0,7$ \\
Amarelo & 91,2 & 90,1 & 91,8 & $91,8 \pm 0,1$ \\
Azul & 91,7 & 91,9 & $\mathbf{8 9 , 0} \pm \mathbf{3 , 3}$ & $89,4 \pm 3,0$ \\
Total & $\mathbf{9 0 , 2} \pm \mathbf{2 , 2}$ & $\mathbf{8 9 , 2} \pm \mathbf{3 , 3}$ & $\mathbf{8 5}$ \\
\hline \multicolumn{5}{c}{$\mathbf{P E T} \boldsymbol{r}$} \\
\hline Corante & \multicolumn{5}{c}{86,9} & $87,6 \pm 0,8$ \\
\hline Vermelho & 88,5 & 87,3 & 90,8 & $91,2 \pm 0,6$ \\
Amarelo & 91,9 & 91,0 & 90,0 \\
Azul & 92,8 & 92,0 & 92,0 & $92,3 \pm 0,5$ \\
Total & $\mathbf{9 1 , 1} \pm \mathbf{2 , 3}$ & $\mathbf{9 0 , 1} \pm \mathbf{2 , 5}$ & $\mathbf{8 9 , 9} \pm \mathbf{2 , 7}$ & $90,4 \pm 2,4$ \\
\hline \multicolumn{5}{c}{}
\end{tabular}

referência, o procedimento estatístico descrito por Harris $^{[20]}$ foi aplicado para um nível de confiança de $95 \%$ (valor de tabelado, $\mathrm{t}_{95 \%=}$ 4,303).

$\mathrm{O}$ teste $t$ comprovou que não há evidência de significativa diferença entre o rendimento dos fios de PET $c$ e PETr, ou seja, o processo de tingimento (vermelho, amarelo e azul) dos fios mostrou desempenho equivalente para um nível de confiança de $95 \%$. Além disso, através da Tabela 1 também foi verificado que o corante vermelho demostrou uma montagem ligeiramente inferior para os fios de PETc e PETr - entre $86 \%$ e $87 \%$ na média dos três tingimentos para o corante em questão - quando comparado aos corantes amarelo e azul.

As interações moleculares que influenciam diretamente o processo de sorção e fixação do corante são: i) forças eletrostáticas do tipo atração de Coulomb ou interação dipolo-dipolo; ii) ligação de hidrogênio; iii) Forças de van der Waals; e, iv) interações hidrofóbicas. O primeiro caso é típico do tingimento de lã, seda, poliamida e poliacrilonitrila que possuem grupamentos polares e, por isso, são tingidas com corantes catiônicos ou aniônicos. Esses tingimentos, em geral, são mais rápidos em relação ao tingimento do $\mathrm{PET}$, pois utilizam forças de longo alcance. A possibilidade de formação de ligação de hidrogênio, sempre acelera o tingimento e acontece em casos específicos geralmente relacionados aos mesmos tipos de fibras citadas acima ${ }^{[9,10]}$.

Forças de van der Waals, apesar de serem forças de curto alcance, são desejáveis e ocorrem sempre que as estruturas do corante e da fibra favorecem. Tingimentos baseados unicamente em forças de van der Waals são eficientes quando favorecidos por fenômenos de capilaridade. Interações hidrofóbicas ocorrem em meio aquoso, entre fibras de baixa polaridade e corantes pouco polares. Por razões entrópicas, pouco explicadas, ocorre nesse meio uma tendência de associação polímerocorante, bem como a formação de agregados de corante $^{[9,10]}$.

O PET é pouco polar. Por esta razão, seu tingimento não conta com a possibilidade do uso de forças de longo 
alcance. Forças de curto alcance como van der Waals e interações hidrofóbicas deverão ser as forças motrizes do processo de sorção ${ }^{[9,10]}$. Assim sendo, o tingimento equivalente dos fios, conforme demonstrado pela aplicação do teste $t$, foi atribuído ao mecanismo típico de interação entre os corantes e o poliéster que tanto os fios de PET $c$ e PET $r$ foram capazes de desenvolver.

Além disso, os dados obtidos também permitiram concluir que a confecção de têxteis com fios de PETr foi possível ocorrer pelo mesmo processo de tingimento adotado para os fios de poliéster comercial.

\section{Análise da solidez do tingimento dos fios de PETr}

A cor de um tecido representa a própria alma e vida do mesmo. O segmento da tinturaria se encarrega desta tarefa. No entanto, nem sempre a cor, após a utilização da peça (tecido), permanece a mesma. O termo solidez se refere à capacidade dos artigos tingidos de não perderem a coloração com o tempo de uso. Entre outros fatores, a perda de coloração pode ocorrer por meio da dessorção do corante durante lavagem com água, degradação do corante por ação do calor, radiação solar, ação de ácidos ou álcalis ${ }^{[9,10]}$.

Os resultados da Tabela 2 foram discriminados por valores numéricos que variam de 0 a 5 , o que representa desde o grau muito ruim ou zero (indesejável) até o grau excelente ou cinco. Essa referência foi utilizada para fazer comparações de o quanto a amostra sofreu algum tipo de mudança e/ou o quanto o tecido testemunha recebeu da amostra analisada.

$\mathrm{Na}$ análise da solidez da cor ao suor, o objetivo foi avaliar a solidez da cor do substrato (PETr) quando submetido à soluções simulando o suor ácido e alcalino. Neste ensaio, a determinação da solidez de cor ao suor foi conduzida mediante o uso do aparelho perspirômetro $^{[12-19,21]}$.

A unidade de perspirômetro consistiu em uma armação de aço inoxidável, que comportou 30 lâminas separadoras de acrílico ou vidro de $115 \times 60 \mathrm{~mm}$. Vinte amostras, dimensões $100 \times 40 \mathrm{~mm}$, foram colocadas entre as lâminas, sob uma carga de 5 kgf. Para testar a solidez da cor à transpiração, amostras (tecidos, fibras ou fios), em contato com o tecido multifibra adjacente (padrão), foram tratadas em duas soluções diferentes de histidina, uma alcalina e uma ácida. As amostras foram drenadas, sob carga, entre as lâminas separadoras ${ }^{[12-19,21]}$.

Unidades de teste separadas para cada tipo de solução alcalina ou ácida foram usadas a fim de se evitar

Tabela 2. Resultados da caracterização de solidez à cor das amostras confeccionadas com fios de PETr.

\begin{tabular}{lcc}
\hline \multicolumn{1}{c}{ Ensaios } & Alteração & Transferência \\
\hline Solidez da cor à luz & 2 & ---- \\
Solidez da cor ao suor ácido & 5 & 5 \\
Solidez da cor ao suor alcalino & 5 & 5 \\
Solidez da cor à lavagem & 4 & 5 \\
Solidez da cor à água clorada de & $4-5$ & ---- \\
piscina & & \\
Solidez da cor à água do mar & 5 & 5 \\
Solidez da cor à fricção & 5 & $4-5$ \\
\hline
\end{tabular}

a possibilidade de mistura entre as duas. Essas unidades foram colocadas, então, em uma estufa por 4 horas a uma temperatura de $37 \pm 2{ }^{\circ} \mathrm{C}$ (temperatura média do corpo humano). Finalmente, as unidades foram removidas e as amostras retiradas e secas em estufa. A alteração de cor nas amostras e a transferência para os tecidos adjacentes foram avaliadas pela escala cinza, sob luz normalizada com $6500 \mathrm{~K}$ em uma cabine de comparação de cores. O valor mínimo de desempenho foi considerado 1, enquanto o máximo de desempenho foi referenciado com o valor $5^{[12-19,21]}$.

Os resultados encontrados para as amostras de PET $r$ referentes à alteração e à transferência enquadraram-se, tanto para o suor ácido quanto para o suor básico, na categoria 5. Desse modo, pôde-se concluir que as amostras com fios reciclados tingidos responderão de maneira bastante satisfatória quando em contato com o suor.

$\mathrm{Na}$ análise da solidez da cor à lavagem, o objetivo foi avaliar a solidez da cor do substrato (PETr) quando submetido a um processo que simulou uma lavagem caseira e uma lavagem comercial ${ }^{[10,12-19]}$.

Um equipamento, modelo Washtec, juntamente com um tipo de sabão específico, foi utilizado dentro de condições definidas de temperatura, volume de detergente, $\mathrm{pH}$ e tempo. $\mathrm{O}$ tecido a ser testado e o tecido testemunha (geralmente, $100 \%$ algodão e outro $100 \%$ poliéster) foram colocados no equipamento e a avaliação de transferência e alteração da cor foi feita através da comparação entre um corpo de prova lavado e um corpo de prova original usando-se uma escala de cinza. Nesta escala, o grau 5 foi dado ao corpo de prova que não apresenta nenhuma diferença entre a amostra lavada e a amostra original. Por outro lado, o valor 1 foi dado para aquele corpo de prova que apresentou a maior alteração de cor ${ }^{[12-19]}$.

Com base no padrão da escala cinza, as amostras com fios de PETr receberam a classificação 4 para alteração e 5 para transferência. Assim, o resultado indicou que a alteração apresentada não comprometeu a cor real do substrato tingido. Ao mesmo tempo, a transferência também não foi significativa, o que permitiu concluir que houve uma excelente solidez da cor.

Nos ensaios de solidez da cor à água clorada de piscina e a água do mar, o objetivo foi avaliar a solidez da cor do substrato (PETr) quando submetido à uma solução de água clorada, a qual simulou a composição de água de piscina, e a uma solução aquosa salina, a qual simulou a água do mar, respectivamente. Com auxílio do equipamento perspirômetro e seguindo os mesmos princípios dos ensaios anteriores, os corpos de prova de dimensões padronizadas foram submetidos às soluções. Posteriormente, uma avaliação da alteração e/ ou transferência da cor original, por meio da escala cinza, foi conduzida ${ }^{[10,12-19,21]}$.

$\mathrm{O}$ resultado geral do ensaio classificou as amostras de PETr em uma escala intermediária entre 4-5. Tal avaliação foi bastante satisfatória, pois permitiu imaginar um aumento da versatilidade de usos dos fios reciclados.

Embora não tenham sido encontrados na literatura artigos técnicos e científicos específicos para comparação 
com o trabalho aqui exposto, uma possível explicação para os resultados de solidez surgiu do estudo de Mancini e Zanin ${ }^{[22]}$, onde a reatividade de flocos provenientes de garrafas moídas de PET foi testada a $100{ }^{\circ} \mathrm{C}$ e 1 atm em água e em soluções 7,5 M de ácido acético, ácido sulfúrico, acetato de sódio e hidróxido de sódio.

Mancini e Zanin ${ }^{[22]}$ observaram que as soluções de ácido acético e acetato de sódio apresentaram pouca reatividade, assim como as reações com água, não ultrapassando $3 \%$ de despolimerização após cinco dias de reação. Já a reatividade da solução de ácido sulfúrico alcançou cerca de $80 \%$ de degradação no período. Porém, o melhor sistema de despolimerização foi a solução aquosa de hidróxido de sódio, que promoveu até $98 \%$ de degradação em cinco horas de reação.

Como nos ensaios apresentados de solidez, as amostras de PETr foram submetidas à condições muito mais brandas de teste, uma vez que as mesmas simulam situações que serão encontradas em uso diário (efeito de suor, lavagem, água clorada e água do mar), a integridade do tingimento não foi afetada em extensão suficiente para que imperfeições pudessem ser detectadas na comparação com o padrão de referência.

Na solidez da cor à fricção, o objetivo foi avaliar a solidez da cor do substrato (PETr) quando submetido à ação mecânica de fricção em um aparelho chamado crockmeter $^{[12-19]}$.

$\mathrm{O}$ equipamento foi projetado para determinar o grau de cor que pode ser transferido da superfície de um material colorido para outras superfícies através de fricção. O equipamento leva este nome derivado do termo crocking que significa transferência de cor. A amostra de teste foi avaliada em condição úmida e em condição seca quanto à fricção. A avaliação da transferência de cor foi feita usando uma escala cinza (de 1, muito ruim, até 5, muito bom $)^{[12-19]}$.

O resultado deste ensaio também foi bastante satisfatório, oferecendo uma boa oportunidade para a utilização do substrato na aplicação de vestuário para moda praia e lingerie. A classificação encontrada foi entre 4 e 5 para a condição úmida e 5 para a condição seca, o que indicou uma pequena transferência de cor nas condições de teste.

O ensaio de solidez à luz determinou a solidez de cor de materiais têxteis quando submetidos ao efeito da luz artificial, a qual corresponde ao iluminante padrão D65 (luz do dia). Nesse ensaio, o material foi acondicionado e exposto à luz por um período de $40 \mathrm{~h}$. Posteriormente, as amostras foram comparadas utilizando uma escala azul para avaliação à luz padronizada que varia de 1 a 8 . O valor numérico 1 corresponde à uma solidez muito baixa enquanto o valor numérico 8 representa o oposto, ou seja, uma solidez muito alta. Nesta escala, a solidez dobra para cada valor numérico ascendente, ou seja, um valor 8 significa que a solidez encontrada foi 128 vezes maior do que a solidez onde o valor 1 tenha sido determinado ${ }^{[12-19]}$.

Um cuidado para a realização do ensaio foi necessidade dos corpos de prova e as tiras padronizadas da escala azul terem que apresentar dimensões e formas idênticas, a fim de evitar erros de avaliação - superestimação do contraste entre as áreas expostas e as não expostas à luz de uma amostra com área relativamente grande, em comparação com uma amostra com área relativamente pequena ${ }^{[12-19]}$.

$\mathrm{O}$ resultado encontrado para as amostras de PETr foi classificado como de nível 2. Isto significa que o substrato tingido apresentou uma solidez de cor ruim. Assim sendo, os tecidos confeccionados com tais fios apresentariam uma baixa fixação do corante e não manteriam a coloração original se sujeitos à luz solar de forma contínua (esmaecimento da coloração). Em função dos resultados menos expressivos para a solidez da cor à luz, o substrato deve ser avaliado com cautela quanto à possível utilização, por exemplo, para confecção de tecidos da linha de moda praia e piscina.

Santos ${ }^{[23]}$ estudou a modificação de filmes e malhas de poli(tereftalato de etileno) com luz UV e/ou N,Ndimetilacrilamida (DMAAm) para obter uma melhor incorporação dos corantes dispersos azo e antraquinônico em tingimento em meio aquoso ou em $\mathrm{CO}_{2}$ supercrítico. Após o tratamento com luz UV em cabine com aquecimento, Santos ${ }^{[23]}$ observou que ocorre um aumento do conteúdo trans na estrutura do PET, o que permitiu um aumento de cristalinidade com melhor compactação dos cristais e diminuição do tamanho dos mesmos.

Considerando que a exposição das amostras de PETr no ensaio de solidez da cor à luz (iluminante padrão D65) ocasionou modificações estruturais no poli(tereftalato de etileno) e que os fios usados na confecção dos tecidos não foram homogêneos como material (os fios de PETr foram resultado da mistura de resíduos de PET, poliéster comercial e elastano), a fixação prolongada dos corantes nos fios ficou, portanto, comprometida. Assim sendo, o resultado de esmaecimento e nível 2 encontrado, apenas corroborou com o esperado.

\section{Análise do desempenho mecânico dos fios de PETC e PET r}

O ensaio de tração é bastante utilizado como teste para o controle das especificações de entrada de matériaprima. No entanto, os resultados fornecidos pelo ensaio de tração são fortemente influenciados pela temperatura, pela velocidade de deformação, pela anisotropia do material, pelo tamanho de grão, pela porcentagem de impurezas, pela presença de cargas, bem como pelas condições ambientais $^{[24]}$.

Os dados de resistência à ruptura, deformação na ruptura e densidade linear dos fios de poliéster comercial $(\mathrm{PET} c)$ e PET reciclado (PETr) são apresentados na Tabela 3 .

A análise dos dados obtidos permitiu verificar que as amostras usadas de PET $c$ e PET $r$ foram homogêneas, pois apresentaram reprodutibilidade, sobretudo nos resultados de limite de ruptura. Os erros relativos percentuais em cada amostra foram de: $0,24 \%$ no limite de ruptura e $6,94 \%$ na deformação no caso do $\mathrm{PET} c ; 0,19 \%$ no limite de ruptura e 4,01\% na deformação para o PET $r$.

Para comparação das amostras de PETc e PETr quanto ao limite de ruptura, o teste $t$ de Student foi utilizado. O limite de ruptura da amostra de PETc foi considerado como o valor de referência e o teste $t$ foi aplicado para um nível de confiança de $95 \%$. Usando-se o procedimento estatístico descrito por Harris ${ }^{[20]}$ e o valor 
Tabela 3. Resistência à ruptura, deformação na ruptura e densidade linear dos fios de PET $c$ e PETr.

\begin{tabular}{|c|c|c|c|c|c|}
\hline \multicolumn{3}{|c|}{ Poliéster comercial (PETc) } & \multicolumn{3}{|c|}{ PET reciclado (PETr) } \\
\hline Amostra & $\begin{array}{l}\text { Limite de ruptura } \\
(\mathbf{N})\end{array}$ & Deformação (\%) & Amostra & $\begin{array}{l}\text { Limite de ruptura } \\
(\mathrm{N})\end{array}$ & Deformação $(\%)$ \\
\hline 1 & 21,18 & 26,4 & 1 & 20,89 & 28,6 \\
\hline 2 & 21,18 & 24,6 & 2 & 20,89 & 30,6 \\
\hline 3 & 21,28 & 26,0 & 3 & 20,89 & 28,6 \\
\hline 4 & 21,28 & 23,0 & 4 & 20,89 & 30,8 \\
\hline 5 & 21,18 & 22,6 & 5 & 20,99 & 30,8 \\
\hline Média & $21,22 \pm 0,05$ & $24,5 \pm 1,7$ & Média & $20,91 \pm 0,04$ & $29,9 \pm 1,2$ \\
\hline \multicolumn{6}{|c|}{ Densidade linear do fio (tex ou g/1.000 m) } \\
\hline & 17,8 & & & 18,4 & \\
\hline
\end{tabular}

tabelado $\mathrm{t}_{95 \%=} 2,776$, foi determinado que há menos do que uma chance de $5 \%$ de que os fios de PETr apresentem limite de ruptura equivalente aos fios de $\mathrm{PET} c$. O mesmo procedimento estatístico foi adotado para a análise da deformação dos fios. Novamente, o resultado obtido permitiu concluir que há menos do que uma chance de $5 \%$ de que os fios de PETr apresentem deformação equivalente aos fios de PETc.

Mancini et al. ${ }^{[1]}$ investigaram a reciclagem de PET pós-consumo a partir de cinco ciclos sucessivos de moldagem por injeção. De acordo com os autores, houve degradação (o número de grupos terminais carboxílicos aumentou cerca de $300 \%$ da primeira até a quinta reciclagem), aumento da cristalinidade (de $11 \%$ para a garrafa moída para $25 \%$ na quinta reciclagem) e diminuição do alongamento na ruptura e tenacidade.

Embora a degradação possa ser considerada, uma vez que os fios de PETr foram inferiores em desempenho mecânico aos fios de $\operatorname{PET} c$, os dados experimentais obtidos nesta investigação divergiram dos resultados de Mancini et al. ${ }^{[1]}$.

A explicação parece residir na metodologia aplicada. Mancini et al. ${ }^{[1]}$ utilizou, especificamente, garrafas de refrigerante de 2 litros e confeccionou corpos de prova por injeção. Neste trabalho, o desempenho mecânico de fios foi considerado. Fios que foram obtidos a partir de embalagens e garrafas de bebidas carbonatadas, ou seja, o material reciclado usado não apresentou uma homogeneidade equivalente ao de Mancini et al. ${ }^{[1]}$. Além disso, para a confecção dos fios de PETr foram misturados aos resíduos de PET, o poliéster proveniente da reciclagem primária da linha fabril e o elastano comercial.

\section{Conclusões}

A análise técnica do uso de fios de PETr (resíduos de PET de embalagens e garrafas de bebidas carbonatadas misturado com poliéster de reciclagem primária da linha fabril e elastano comercial) foi avaliada neste trabalho. Os resultados experimentais permitiram verificar que:

- O processo de tingimento pôde ser conduzido de forma similar ao processo convencional aplicado ao poliéster comercial;

- O desempenho mecânico dos fios de PETr foi inferior aos fios de PETc. Embora, para as aplicações imaginadas (confecção de vestuário e moda íntima), tal observação não deva ser um fator limitante;

- A solidez do tingimento foi bastante satisfatória, embora quando considerada a solidez à luz, as amostras com PETr tenham tido desempenho ruim. Uma solução necessitaria ser encontrada em caso de extensão do uso dos fios de PETr para moda praia e piscina.

Além destas observações, também pôde ser constatado que a utilização de resíduos de PET (embalagens e garrafas) como matéria-prima careceu de homogeneidade. Consequentemente, uma análise real de uso do PETr somente será obtida quando houver uma efetiva coleta e separação seletivas do PET.

\section{Agradecimentos}

Os autores agradecem aos órgãos de fomento (CAPES, CNPq e FAPERJ) pelo suporte financeiro; as indústrias UNIFI (Alfenas/MG) e Triumph International (Nova Friburgo-RJ) pela doação da matéria-prima e confecção dos tecidos; e, ao SENAI/CETIQT pela realização dos diferentes experimentos.

\section{Referências Bibliográficas}

1. Mancini, S. D.; Bezerra, M. N. \& Zanin, M. - Polímeros, 8, p.68 (1998).

2. Grippi, S. - "Lixo, reciclagem e sua história", Editora Interciência, Rio de Janeiro (2001).

3. Spiro, T. G. \& Stigliani, W. M. - "Química Ambiental", 2. ed., Pearson Prentice Hall, São Paulo (2008).

4. Teófilo, E. T.; Melo, R. N.; Silva, S. M. L. \& Rabello, M. S. - Polímeros, 19, p.202 (2009).

5. Ferreira, C. T.; Da Fonseca, J. B. \& Saron, C. - Polímeros, 21, p.118 (2011). http://dx.doi.org/10.1590/S010414282011005000029

6. Agência Nacional de Vigilância Sanitária - ANVISA "Resolução RDC n 20, de 26 de março de 2008", Diario Oficial da República Federativa do Brasil (2008).

7. Associação Brasileira da Indústria do PET - ABIPET. Disponível em: <http://www.abipet.org.br/>. Acesso em: jun. 2012.

8. Romão, W.; Spinacé, M. A. S. \& De Paoli, M. A. Polímeros, 19, p.121 (2009). 
9. Zollinger, H. - "Color Chemistry: Syntheses, Properties and Aplications of Organic Dyes and Pigments", 2nd ed., VCH, New York (1991)

10. Pereira, G. S. - "Introdução à tecnologia têxtil. Apostila do curso têxtil em malharia e confecção, módulo II", Centro Federal de Educação Tecnológica de Santa Catarina, Unidade de ensino Aranguá (2010).

11. International Organization for Standardization - ISO - "ISO 2062/2009: Textiles - yarns from packages. Determination of single-end breaking force and elongation at break using constant rate of extension (CRE) tester", ISO (2009).

12. Associação Brasileira de Normas Técnicas - ABNT "NBR ISO 105-A01:2011: Têxteis - Ensaios de solidez da cor. Parte 1: Princípios gerais de ensaio", ABNT (2011).

13. Associação Brasileira de Normas Técnicas - ABNT. "ABNT NBR ISO 105-A02:2006: Têxteis - Ensaios de solidez da cor. Parte A02: Escala cinza para avaliação da alteração da cor”, ABNT (2006).

14. Associação Brasileira de Normas Técnicas - ABNT. "ABNT NBR ISO 105-A03:2006: Têxteis - Ensaios de solidez da cor. Part A03: Escala cinza para avaliação da transferência da cor", ABNT (2006).

15. International Organization for Standardization - ISO "ISO 105-A04:1989: Textiles - Tests for colour fastness-Part A04: Method for the instrumental assessment of the degree of staining of adjacent fabrics", ISO (1989).

16. International Organization for Standardization - ISO "ISO 105-A05:1996: Textiles - Tests for colour fastness--
Part A05: Instrumental assessment of change in colour for determination of grey scale rating", ISO (1996).

17. International Organization for Standardization - ISO "ISO 105-B01:1994: Textiles - Tests for colour fastness Part B01: Colour fastness to light: Daylight", ISO (1994).

18. International Organization for Standardization - ISO - "ISO 105-B03:1994: Textiles - Tests for colour fastness - Part B03: Colour fastness to weathering: Outdoor exposure", ISO (1994).

19. International Organization for Standardization - ISO - "ISO 105-B06:1998: Textiles - Tests for colour fastness-- Part B06: Colour fastness and ageing to artificial light at high temperatures: Xenon arc fading lamp test”, ISO (1998).

20. Harris, D. C. - "Análise Química Quantitativa”, 7. ed., LTC, São Paulo (2008).

21. Gamine Textile - "Equipamentos nacionais / perspirômetro". Disponível em: <http://www.gaminetextile.com/ equipamentos>. Acesso em: jan. 2011.

22. Mancini, S. D. \& Zanin, M. - Polímeros, 12, p.34 (2002). http://dx.doi.org/10.1590/S0104-14282002000100010

23. Santos, W. L. F. - "Modificação e tingimento de filmes e malhas de poli(tereftalato de etileno)", Tese de Doutorado, Universidade Estadual de Maringá, Brasil (2005).

24. Garcia, A.; Spim, J. A. \& Dos Santos, C. A. - "Ensaios dos materiais", LTC, São Paulo (2000).

Enviado: $25 / 06 / 12$

Reenviado: $24 / 10 / 12$

Aceito: $21 / 11 / 12$ 